Although there is a great deal of useful material in this volume for the paediatrician with an interest in gut and liver immunology, it focuses for the most part on adult disease. As a paediatric gastroenterologist, I would like to have seen more on the rare but clinically challenging subject of autoimmune enteropathy. Strobel's chapter on food intolerance and allergy is particularly useful and includes the intriguing hypothesis that imbalance in cytokine pathways could trigge mechanisms which, once activated in an antigen specific manner, may not be reversed or halted by the mere withdrawal of the specific trigger; this may explain diet resistant coeliac disease, autoimmune gastroenteropathies, and the syndrome of intractable diarrhoea of infancy. Following from this arise two crucial questions, namely, how can primary sensitisation be prevented and how can clinical (and immunological) tolerance be restored in the sensitised child? Let us hope that it will not be a further 20 years before immunologists are able to provide the answers.

PETER B SULLIVAN

University lecturer in paediatrics honorary consultant paediatrician

Textbook of Paediatric Nutrition. 3rd Ed Edited by D McLaren, D Burman, N Belton, A Williams. (Pp 632; £97.50.) Churchil Livingstone, 1991. ISBN 0-443-04090-7.
Infant nutrition has been the topic of many erudite dissertations over the millennia of physicians' writing. Many of the earlier works have been little other than pontifications; now we are privy to much research and many recommendations, is the end product based on science or pontification by august committees and bodies?

Nutrition perforce covers all areas of medicine and social development. It is a vital aspect of many disease processes and can affect prognosis, as indicated in the chapter on renal disease. However, because applications of nutrition are protean, it can be difficult to pitch a general text at the right level. Should such a text merely educate general paediatricians as to the nutritional niceties of sometimes rare medical conditions or should the tome enter into sufficient detail to guide the specialist in the field? I am not clear whether this question has been considered in great detail by the editors, as the details of nutritional advice in many chapters vary from very detailed, as in renal disease, to generally broad based concepts, as in that on diabetes. The book competes in regard to nutritional treatment of children with, for example, Diets for Sick Children by Dorothy Francis.

Nutrition, like all aspects of medical and public health knowledge is changing rapidly. For example, the nutritional approach to diabetes is being re-examined so the recommendations of the diabetes chapter cannot reasonably be utilised. For general paediatricians, this is a disadvantage. If there are areas within a textbook that do not match with one's own experience, it makes the nonspecialist rather insecure in using advice given in other chapters in case it has also been superseded. This criticism of contemporaneity is an easy one to level but I feel should be considered by those editing a book which will be consulted for several years before being updated.

I believe a book such as this should give an overview of the nutritional principles attached to the treatment of various diseases. As such, the final section on community nutrition was informative, enjoyable, and pitched at the right level. The concept of adult disease having its origins in infancy is as old as medical philosophy but is an area of immense importance as interventions on a population wide basis can have significant influence on the health of a nation and the health burden of society. I enjoyed reading Dr Dennis Burkett's seminal contributions on the role of fibre and his approach expanded into several other areas of adult illness. Again, however, we must remain cognisant of the rapidity with which nutritional fads waft through society and the speed with which recommendations for butter or against butter, etc, are splashed across screen and paper alike. I return, therefore, to my first paragraph; have we really moved on that much from pontification? STEPHEN J ROSE
Consultant paediatrician 


\section{Treatment of infantile spasms}

Infantile spasms should be treated with nitrazepam and a month of corticotrophin followed by two months of prednisolone unless the year ends with an odd number and your grandmother was born on a Wednesday when sodium valproate and prednisolone for six weeks are de rigueur, although you could make do with vigabatrin and three weeks of hydrocortisone if your favourite colour is blue and Jupiter is about to collide with Mars.

Exactly how people treat children with infantile spasms often owes more to geography, tradition, and fashion than to science. In the past most children in Britain were treated with injected corticotrophin but a switch to oral steroid was imposed by commercial diktat rather than professional consensus. Some have argued against the use of steroids in symptomatic cases and vigabatrin has been advocated especially in children with tuberous sclerosis.

Doctors in Paris (Emilie Schlumberger and Olivier Dulac, Developmental Medicine and Child Neurology 1994; 36: 863-72) have recently described their results with short course steroid treatment in 94 patients (33 cryptogenic, 61 symptomatic). Their study is uncontrolled but they claim that their results are as good as anybody else's. They treated both cryptogenic and symptomatic cases apart from those with brain malformations, who respond poorly to treatment, and those with tuberous sclerosis whom they treat with vigabatrin. All patients in the study were treated initially for two weeks with oral hydrocortisone (15 mg/kg body weight/day) and sodium valproate (dose increased gradually to $40 \mathrm{mg} / \mathrm{kg} /$ day over the first week). The sodium valproate was continued until between 12 and 18 months of age but after two weeks the hydrocortisone was tailed off over a further two weeks in 70 patients (30 cryptogenic, 40 symptomatic) whose spasms had stopped and whose EEGs no longer showed hypsarrhythmia or epileptic discharges. Of the 24 patients whose spasms or EEG abnormalities persisted after two weeks of treatment 15 were then given tetracosactrin $(0.1 \mathrm{mg} / \mathrm{kg} / \mathrm{day})$ for two weeks followed by oral hydrocortisone $10 \mathrm{mg} / \mathrm{kg} /$ day gradually tailed off over one month. Nine of these 15 responded to this further treatment.

Of 33 patients with cryptogenic infantile spasms 30 (91\%) responded to treatment within two weeks and another two responded after treatment with tetracosactrin. After two years or more of follow up $25(76 \%)$ were still seizure free and $18(55 \%)$ were both seizure free and intellectually normal. In the 61 patients with symptomatic disease $40(65 \%)$ responded to the first two weeks of treatment and a further seven responded after tetracosactrin. After two years $28(46 \%)$ of the 61 were seizure free and eight $(13 \%)$ were both seizure free and intellectually normal. Symptomatic patients with periventricular leukomalacia, porencephaly, or postnatal brain damage responded to treatment better than those with neonatal hypoxia at term or those whose brain disease was of undetermined cause.

One child died of disseminated tuberculosis during hydrocortisone treatment, three became hypertensive, four had bouts of axial hypertonia, and eight became noticeably cushingoid in appearance. These authors call for controlled trials of various treatments concentrating on response according to aetiology. The number of trials that could be performed is large and multicentre trials would presumably be necessary to provide reliable answers. 